\title{
Floatainer, plataforma modular flutuante: proposta ao concurso UnBox 2017
}

\author{
Floatainer: modular floating plataform: UnBox 2017 competition proposal
}

Marcele Marin ${ }^{1}$, André Boeira Ivanov², Carlos Alexandre de Souza Gonçalves ${ }^{3}$ e Samuel Silva de Brito ${ }^{4}$

${ }^{1,2,3,4}$ Universidade Federal de Santa Maria, Cachoeira do Sul, Brasil

marcelemarin@hotmail.com; andre.b.ivanov@gmail.com ; carlosxanderg@hotmail.com ; samuel.brito@ufsm.br

\section{Resumo}

Este trabalho apresenta os desafios da proposta projetual recentemente realizada por alunos do Curso de Arquitetura e Urbanismo da Universidade Federal de Santa Maria do Campus de Cachoeira do Sul em um concurso internacional de arquitetura e design promovido pelo portal Volume Zero, que, através do concurso "UnBox 2017", propunha formas de repensar criativamente o descarte de contêineres no mundo contemporâneo. O resultado final obtido foi dotado de significativo valor arquitetônico, em especial devido à flexibilidade de seu programa de necessidades e de seu local de implantação. Sua maior contribuição se dá através dos valores ambientais, sociais e economicamente sustentáveis, evidenciado por sua materialidade composta majoritariamente por elementos reutilizados: contêineres e tambores plásticos. Outro fator relevante foi o conhecimento resultante da experiência oferecida aos acadêmicos por meio da participação em concurso internacional de arquitetura e design. Por conseguinte, considera-se totalmente positiva a prática de participação em competições que estimulem a criatividade, a inovação e a busca por ferramentas ao desenvolvimento sustentável.

Palavras-chave: Concurso de arquitetura; Contêineres; Sustentabilidade

\section{Abstract}

This article aims to present a proposal recently designed by students of the Architecture and Urbanism Course of the Federal University of Santa Maria Campus of Cachoeira do Sul in an international competition of architecture and design promoted by the portal Volume Zero, "UnBox 2017", wich proposed ways to creatively rethink the discard of containers in the contemporary world. The final result was punctuated by a distinguished architecture value, especially due to the flexibility of its program and its deployment location. However, its highest value is its social importance: the materiality is mainly composed of reused elements - containers and plastic drums (chosen precisely because of its reusable character, just as containers) -, making it environmentally, socially and economically sustainable. Another pertinence factor to be explored is the resulting knowledge to the students through the participation in competitions of architecture and design. Therefore, the practice of participation in competitions that stimulate creativity, innovation and the search for tools for sustainable development is considered totally positive.

Keywords: Architecture competition; Containers; Sustainability 


\section{Introdução}

A plataforma digital internacional intitulada Volume Zero, que tem por finalidade o compartilhamento de conhecimentos no âmbito da arquitetura e do design, evidenciando o rigoroso processo por trás da transformação de um conceito em algo concreto e de valor, lançou no ano de 2017 o concurso "UnBox 2017", que propunha repensar o uso de contêineres. Assim como este concurso, o portal traz diversas competições em que a criatividade e a inovação são as ferramentas para a proposição de projetos que ajudem a resolver problemas da sociedade contemporânea.

A pertinência do tema em questão ultrapassa a necessidade de justificativa, afinal o mundo atual sofre cada vez mais com problemas de ordem ambiental, e a partir disso surgem diariamente esforços na tentativa de reverter a atual situação e o previsível futuro ao qual nos encaminhamos. Mas ainda assim essas preocupações são vistas por muitos com ceticismo, como mera tendência e estratégias de "marketing", ou mesmo adorno cênico superficial ao enfrentamento da problemática, e dessa forma descaracterizando a importante urgência em trabalhar a pauta ecológica, desmascarando interesses econômicos e políticos que permeiam a questão. Dessa forma torna-se ainda mais impreterível as discussões e, principalmente, ações em relação ao rumo do panorama ambiental global, buscando-se atenuar ou reverter esse quadro de constante degradação e exploração de recursos naturais.

O conceito de sustentabilidade, entendido enquanto palavra-chave norteadora de um processo projetual consciente perante a conjuntura apresentada, reflete a imprescindibilidade de uma proposta que se sustente em um sistema ecológico e social, ou seja: seja economicamente viável e ambientalmente benéfica.

Sensibilizados por essa necessidade de iniciativas que visam alterar esse cenário, três estudantes do Curso de Arquitetura e Urbanismo da UFSM do Campus de Cachoeira do Sul acudiram ao chamado do concurso UnBox 2017. A inscrição dos acadêmicos foi motivada por uma publicação feita em uma rede social, na qual o portal Volume Zero anunciava o concurso. Apesar dos alunos estarem vivenciando o fim do semestre letivo, e portanto sobrecarregados com diversos trabalhos de disciplinas que finalizavam, assumiram o desafio e realizaram a inicial inscrição no dia 07 de dezembro de 2017 , 62 dias após o lançamento do concurso. O prazo para o envio da proposta, que tinha que ser realizada em uma única prancha de formato A1, encerrava-se no dia 15 de janeiro de 2018, às 23h59 - segundo o fuso horário da Índia (GMT + 5:30). Os elementos mínimos de entrega especificados no edital exigiam planta baixa, uma vista seccionada (corte), um detalhamento em escala apropriada e uma perspectiva ilustrativa da proposta, além do texto que apresentava e defendia o projeto.

\section{Metodologia}

Na primeira reunião de trabalho com o professor orientador, docente que o grupo de alunos tinha convidado na busca de uma tutoria motivadora, estabeleceram-se as diretrizes e intenções para a proposta, assim como os objetivos finais a serem atingidos. Desse modo, entrou-se em concordância quanto à organização do cronograma e das diferentes etapas abarcadas pelo processo projetual. Com base na definição da ideia central, iniciou-se o desenvolvimento da proposta, utilizando-se, para tal, moldes de papel em escala reduzida (1/200) dos contêineres. Estes, por sua vez, poderiam ser utilizados em uma quantidade de até 4 contêineres, na dimensão de 10, 20 ou 40 pés. Optou-se pela utilização de 4 contêineres de 40 pés, a partir da aplicação destes enquanto estrutura e revestimento de forma isolada, resultando em 4 painéis de cobertura, 8 painéis laterais, 4 painéis de base (estruturais), 4 portas duplas e 4 painéis posteriores. Para se trabalhar com a flutuação (uma das diretrizes definidas inicialmente), resolveu-se utilizar os tambores plásticos devido à sua similaridade ao contêiner nos âmbitos de disponibilidade (tornando-o economicamente viável) e sustentabilidade (por ter o caráter reutilizável, podendo, assim, ser empregados 
tambores já usados). Desse modo foram necessários 240 tambores de 200L de capacidade, de acordo com um prédimensionamento da carga a ser sustentada pela base de contêineres. Formalmente foram analisadas diversas possibilidades de arranjo e distintas conformações das partes dos contêineres (Figura 1), até que se alcançasse o resultado espacial pretendido (Figura 2).

Figura 1 - Estudos de organização espacial da base flutuante

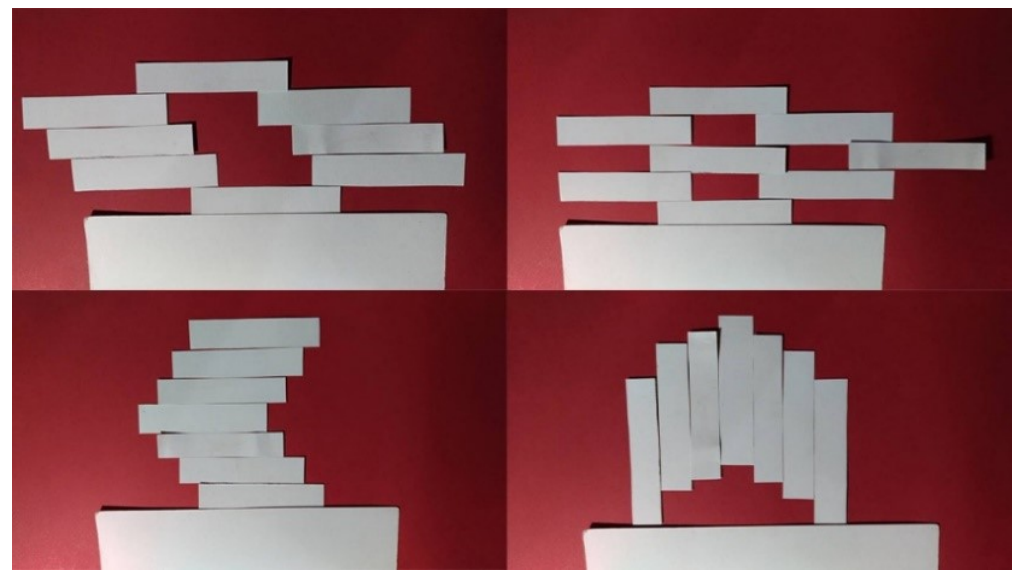

Figura 2 - Estudo final de configuração espacial

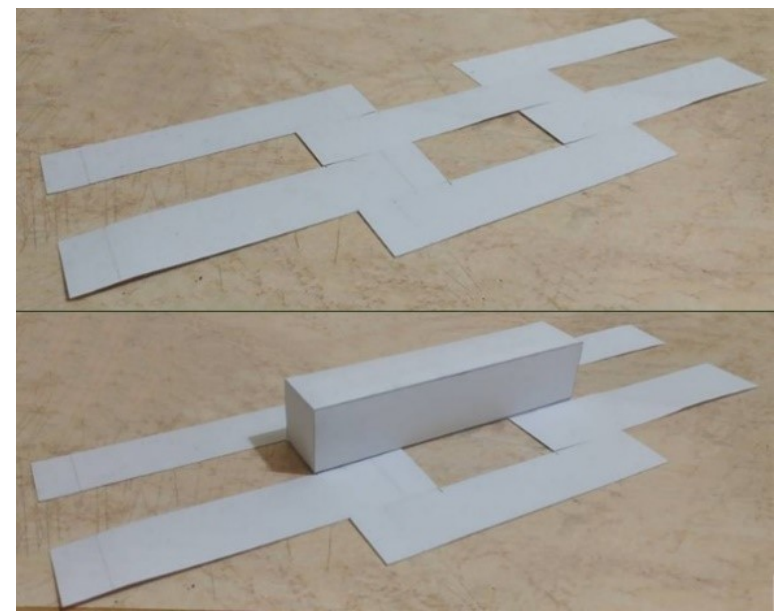

\section{Resultados e discussão}

A proposta projetual desenvolvida no concurso se intitula Floatainer, resultante da associação da palavra em inglês "float" com "container", e se define como uma base flutuante, modular e multifuncional. Utilizando-nos da busca por novos espaços públicos que qualifiquem a cidade de Cachoeira do Sul, procuramos quebrar o padrão vigente propondo um espaço flutuante sobre o Rio Jacuí, associando o uso de novas técnicas, materiais e formas, com a implementação de um espaço novo que "recicla" também o valor social das margens deste rio tão importante e tão esquecido na rotina urbana da cidade.

O projeto deve ser entendido como um elemento com grande potencial construtivo (possui resistência a grandes cargas e mudanças climáticas), além de possuir abundante disponibilidade material, possibilita um maior contato com 
estratégias sustentáveis e alternativas ao desenvolvimento urbano consciente. Tais características foram ressaltadas no projeto proposto através de suas diretrizes, como a flexibilidade, tornando-o adequável a diversas necessidades e locais de implantação.

A proposta foi criada a partir do desmembramento dos contêineres, utilizaram-se 7 painéis (laterais e de base estrutural) para a formação da plataforma flutuante, gerando uma área útil de $176 \mathrm{~m}^{2}$. Ao centro, possibilitou-se a colocação de um contêiner em sua volumetria original, adaptando-se apenas os fechamentos para fins de acesso, circulação, iluminação e ventilação. A disposição espacial foi pensada para que se torne possível a conexão entre diferentes plataformas replicadas, possíveis de se associarem de distintas formas, criando, assim, inúmeras possibilidades de modulação e de espaços públicos com diversificadas propostas: lazer, esporte, cultura, saúde, etc.

A partir desta modulação é possível criar diferentes arranjos espaciais que passam a configurar uma nova orla em rios e lagos, espaços que são majoritariamente subutilizados e esquecidos. Oferecendo uma estrutura com espaços adequados para receber diversas possibilidades de programa (centros culturais, ambulatórios, bibliotecas, etc.), é capaz de atender às necessidades específicas de cada localidade. Além de poder ser transportada de um lugar para outro, a plataforma torna-se adaptável a inúmeros contextos, inclusive possibilitando sua implantação em locais de risco ou de difícil acessibilidade.

O resultado final apresentado na prancha submetida ao concurso (figura 3 ) foi disposto de forma a proporcionar uma leitura intuitiva e de fácil compreensão por meio da expressão gráfica. O texto explicativo deveria possuir no máximo 200 palavras e estar no idioma inglês. Assim, as imagens deveriam traduzir visualmente o projeto de forma atrativa e simplificada.

Por meio de 4 esquemas gerais - formação estrutural, possibilidades volumétricas, de programa / uso e de modulação - foi possível expressar as principais funcionalidades e atributos da proposta. Os desenhos técnicos (planta baixa e vista seccionada) e a perspectiva geral foram feitos utilizando-se o desenho à mão, e então complementados com o uso do software Photoshop, empregado também na elaboração dos demais elementos gráficos.

Figura 3 - Prancha submetida para avaliação no concurso

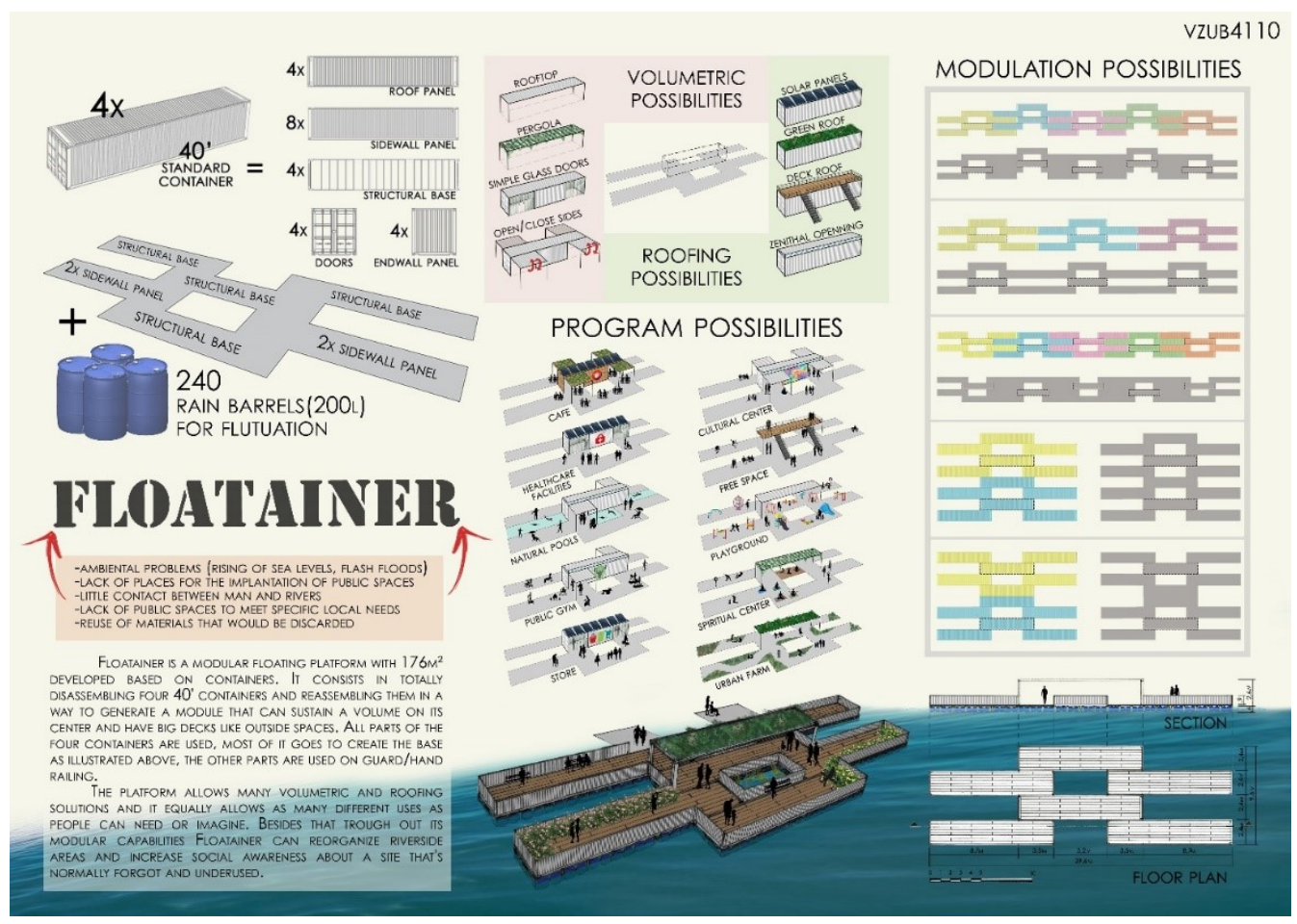




\section{Conclusões}

Perante o atual panorama ambiental, social e urbano em que vivemos, proposições que explorem alternativas sustentáveis para problemas enfrentados por nossa sociedade devem ser discutidas e compartilhadas. A pertinência desta proposta projetual está intimamente ligada às problemáticas que ela abrange. Com a elevação do nível dos mares devido ao aquecimento global e desastres socioambientais como enchentes e inundações, torna-se imprescindível a adaptação dos modelos de cidade contemporânea às novas condições de vida. A falta de locais para implantação de espaços públicos nos meios urbanos, principalmente nas cidades já consolidadas, é inquietante, assim como a carência de equipamentos públicos estruturantes da qualidade de vida. Desse modo, encontrar maneiras de habitar superfícies aquáticas talvez seja uma das alternativas mais sensatas, viáveis e eficazes, sobretudo para cidades localizadas na beira de rios, lagoas e mares.

A participação em concursos que estimulem novas formas de pensar, projetar e habitar é de extrema relevância na formação acadêmica, profissional e intelectual, principalmente no âmbito da arquitetura e do urbanismo. E apesar deste projeto não ter logrado a classificação e premiação pretendida no concurso, a oportunidade de ampliar a formação acadêmica junto a um certame internacional ambientalmente comprometido com a inovação social, e ter proposto uma resposta simultaneamente compromissada com a nossa cidade de Cachoeira do Sul, sua sociedade e recursos naturais, nos traz a certeza que esta efêmera experiência é uma valiosa contribuição para transformação do panorama atual.

\section{Referências}

ASSOCIAÇÃO BRASILEIRA DE NORMAS TÉCNICAS. NBR 9050: Acessibilidade de pessoas portadoras de deficiências a edificações, espaço, mobiliários e elementos urbanos. Rio de Janeiro, 2015.

CHING, Francis. Arquitetura: forma, espaço e ordem. São Paulo: Martins Fontes; 1998.

HERTZBERGER, Herman. Lições de Arquitetura. São Paulo: Martins Fontes; 1996.

LYNCH, Kevin. A Imagem da Cidade. São Paulo: Martins Fontes; 1997.

NEUFERT, Ernest. Arte de projetar em arquitetura. São Paulo: Gustavo Gili; 1996. 